\title{
Congelación bacteriana: Factores que intervienen en el proceso
}

\author{
Ligia Consuelo Sánchez Leal', Lucía Constanza Corrales Ramírez \\ ${ }^{1}$ Programa de Bacteriología y Laboratorio Clínico, Facultad Ciencias de la Salud, Universidad Colegio Mayor de Cundinamarca
}

\section{Introducción}

El objetivo que se plantea hoy en día frente a la microbiología es el de conocer y aprovechar todo el potencial metabólico de los microorganismos y transformarlos en biomasa que beneficie otras especies en la naturaleza.

Los microorganismos, por mucho tiempo, han sido vistos por el hombre como un enemigo y ello generó una guerra que debe concluir. Los nuevos conocimientos y tecnologías han dado una nueva perspectiva al mundo microbiano y se hace necesario establecer una alianza o colaboración estratégica que permita remediar en conjunto situaciones que han sido causadas por la vivencia no recapacitada e irresponsable por parte de los seres humanos durante muchos siglos.

En este sentido, el propósito de la ciencia microbiológica debe ser el de preservar las especies bacterianas en condiciones que permanezcan genéticamente estables, aunque por situaciones de adaptabilidad manifiesten cambios fenotípicos transitorios.

Los microorganismos pueden ser conservados para su posterior estudio o utilización a través de diferentes métodos. La congelación se ha convertido en la elección con más ventajas y por ello es necesario considerar los diferentes factores que están implicados en este proceso: papel de la membrana, estrés bacteriano, criopreservantes y medios de conservación. La revisión de estas variables constituye el primer paso del proyecto Métodos óptimos de conservación de la microdiversidad autóctona.

En la tendencia de recuperar la interacción orgánica se crea la necesidad de utilizar los microorganismos como fuentes dinámicas que produzcan transformaciones en los microsistemas, en la síntesis de sustancias, en el biocontrol por lo tanto se requiere identificar, caracterizar, conservar y preservar las cepas que tienen importancia en estas aplicaciones.

Para dar respuesta al anterior propósito, se indagó acerca de diferentes factores que intervienen en la adaptación bacteriana al proceso de congelación

\section{Congelación bacteriana}

La congelación bacteriana es un método físico químico que permite conservar microorganismos viables por un tiempo sin sufrir cambios genotípicos. En este proceso se involucra el agua como microambiente y es ella la que cambia su estado de líquido a sólido; de otro lado, la bacteria inmersa en este medio debe adaptarse a las condiciones de este nuevo ambiente, transformar la velocidad de su metabolismo, conservar su viabilidad y evitar que los cristales de hielo formados por el cambio de temperatura del agua le ocasione algún daño.

En el proceso de adaptación bacteriana inducido por la congelación, es significativa la reducción en la velocidad metabólica, a tal punto que su metabolismo se hace imperceptible, pero suficiente para mantener el microorganismo vivo. Algunas de estas adaptacio- 
nes son: la producción de enzimas resistentes al frió, sistemas de transporte adaptados a bajas temperaturas, el aumento de la concentración de ácidos grasos en la cadena de fosfolípidos de la membrana celular, esta última, para que continúe el estado semifluído de la membrana y evitar la congelación.

\section{Factores relacionados con la adaptación bacteriana al proceso de congelación}

\section{Microambiente}

En la naturaleza se encuentra una gran diversidad de ambientes que no cumplen con condiciones óptimas para el desarrollo de organismos superiores, sin embargo, encontramos organismos microscópicos perfectamente adaptados. El tamaño se constituye en una ventaja ya que por ser organismos tan pequeños, su ambiente también lo es, y por lo tanto esto le otorga versatilidad para que en espacios y tiempos muy reducidos las condiciones físico-químicas cambian y les permite adaptarse y desarrollarse (1-9).

El ambiente que rodea a un ser vivo es un mundo complejo que incluye componentes bióticos (otros organismos vivos) y abióticos (compuestos no vivos); este espacio para los microorganismos bacterianos ha sido denominado microambiente; la interacción que surge en estos espacios es muy dinámica, la mayoría de las comunidades vivas que lo componen establecen relaciones de cooperación pero también de antagonismo que conlleva a cambios permanentes en los procesos de adaptación de las poblaciones bacterianas (9-10).

La bacteria se relaciona con el microambiente que la rodea a través de movimientos, si se rodea de una sustancia química, la sustancia atrae la bacteria si es favorable para ella; si no le es favorable, la respuesta es alejarse de el. Estos movimientos dirigidos hacia una molécula señal se denominan taxias y están controlados por mecanismos moleculares. Esto le permite reconocer sus espacios favorables, modificarlos si puede, adaptarse o alejarse de ellos. (8)
La capacidad que tienen los microorganismos de transformar las propiedades físicas, químicas y biológicas del ambiente en que se encuentran en cualquier condición, se acentúa aún más en condiciones no favorables en las cuales se ven abocados a originar cambios significativos y rápidos en sus actividades metabólicas. $(1,12)$

\section{Membrana Citoplasmática}

En la criopreservación bacteriana, es indispensable considerar el papel que juega la membrana citoplasmática, ya que actúa como barrera esencial y separa el interior del exterior celular. Así mismo, es necesario tener en cuenta que en situaciones, medios y ambientes hostiles y adversos no logra por si sola defender su estructura y conservar su arquitectura papel que es asumido por la pared (6).

La composición de la membrana bacteriana es una bicapa lipídica hidrofóbica compuesta por ácidos grasos, así como unidades hidrofílicas como el glicerol hacia el exterior, posee un gran contenido de proteínas que se mueven libremente a través de la bicapa; de esta forma la membrana expresa dos cualidades la elasticidad y la permeabilidad.

La estructura multifuncional que posee la membrana le permite llevar a cabo procesos metabólicos esenciales para la preservación de la viabilidad microbiana, razón por la cual, en los procesos de congelación pese a que la célula es sometida a cambios biofísicos y químicos del ambiente, logra adaptarse; una hipótesis de lo que sucede en este proceso, está relacionada directamente con el transporte pasivo que la célula hace con el agua, donde la no utilización de protectores llevaría a la salida de agua del interior de la célula para compensar el aumento de las concentraciones de soluto en el exterior a consecuencia de la formación de núcleos de hielo.

Otro aspecto importante para considerar es el relacionado con el tamaño de las células procarióticas, en términos generales el hecho de que sean células tan pequeñas les ofrece una serie de ventajas biológicas. 
A menor tamaño, mayor velocidad y eficiencia en el intercambio de nutrientes Una de estas ventajas es la relacionada con el "ritmo con el que los nutrientes y las sustancias de desecho pasan del interior al exterior de las células y viceversa, el cual es generalmente inversamente proporcional al tamaño de la célula, por lo tanto este flujo afecta los ritmos metabólicos y de crecimiento" (1). Por lo tanto la velocidad de transporte es directamente proporcional a la superficie de la membrana celular, situación que explica por que las células procarióticas alcanzan mayores tamaños de población en espacios cortos de tiempo, debido por supuesto a las mayores tasas de crecimiento. "Estas tasas de crecimiento y los tamaños de población alcanzados permiten causar cambios en la fisicoquimica de su ecosistema en tiempos relativamente cortos" (1).

Claro está, todo este recambio se realiza a través de la membrana plasmática la cual a pesar de su alta permeabilidad actúa a la vez como filtro seguro en el cumplimiento de todas las funciones fisicoquímicas, nutricionales, desintoxicantes y de adaptación al medio ambiente impidiendo así el paso libre de los compuestos polares, compuestos pequeños no polares y sustancias solubles en fases hidrofóbicas como por ejemplo los ácidos grasos, los alcoholes y bencenos, sustancias polares que son capaces de atravesar la barrera libremente gracias a la solubilidad en la fase lipídica. Si esta se rompe, sencillamente la viabilidad de la célula finaliza. (6)

\section{Estrés bacteriano}

El estrés es una situación que condiciona cambios de adaptación en la bacteria, normalmente este es un estado transitorio que le permite tener condiciones de resistencia a la hostilidad, situación que finaliza cuando las condiciones de estrés se eliminan (7).

Uno de los mayores problemas a los que puede llevar este estrés es generarle cambios que pueden ser transitorios o permanentes en su actividad enzimática, capacidad antigénica o viabilidad. (6)
Se ha visto que los procesos de enfriamiento, así sea natural, para las bacterias que tienen que soportar cambios bruscos de temperatura en las zonas polares y templadas o provocado como es el caso de congelación ex situ, generan una adaptación que incluye entrar en un periodo de latencia, donde la actividad enzimática disminuye notablemente e incluso podría decirse que se detiene. Al respecto, algunos autores han denominado este proceso estado "transitorio no cultivable" (transiently non-culturable state) (2) en el cual se presume que el microorganismo utiliza una estrategia especial de supervivencia en la cual suceden cambios morfológicos, fisiológicos y genéticos, por activación de reguladores transcripcionales o postranscripcionales. La finalización del estado de no culturabilidad ha sido denominada resucitación. (2)

Algunos autores han establecido nuevos conceptos en torno al stress que produce la congelación. Uno de ellos es el de starvation survival o estado de hambre (2), es el término que se le ha dado a los microorganismos en estado de congelación en el cual la bacteria conserva una alta actividad metabólica que le permite soportar el metabolismo del núcleo y continuar con los mecanismos de reparación celular, de tal forma que permanece la capacidad de culturabilidad, una vez cese el estado de stress(13).

Igualmente sostienen que en condiciones de stress, se activan varios sistemas, uno de ellos, el de guanosin tetrafosfato el cual le confiere a la célula la posibilidad de aumentar la vida media de su RNA mensajero; el almacenamiento de reservas de energía y fosfato

\section{La actividad biológica bacteriana y las reacciones al frío}

La diversidad estructural y funcional que se observa en las bacterias representa un conjunto de éxitos evolutivos adquiridos a través del proceso de la selección natural confiriendo así un valor de supervivencia y adaptabilidad muy alto a las bacterias de hoy, sin embargo, no todos los microorganismos 
toleran de la misma forma un determinado cambio ambiental. Esto puede generar diversas reacciones, unas bacterias sufren efectos nocivos, para otras es indiferente y algunas se verán beneficiadas.

Algunas hipótesis propuestas por investigadores sobre los fenómenos celulares que ocurren en las células bacterianas al ser sometidas, permiten exponer los siguientes planteamientos:

Uno de los cambios físico químicos que afecta la actividad biológica bacteriana es la temperatura, incidiendo directamente sobre la velocidad de crecimiento. Investigadores han observado que las bajas temperaturas tienen un efecto directo sobre la fluidez de la membrana provocándose por ello la detención de los procesos de transporte a través de la membrana y por lo tanto el recambio de protones.

Otro efecto visualizado por las bajas temperaturas es el aumento en la viscosidad del citoplasma generando dificultad en el intercambio metabólico de los procesos vitales del microorganismo. Esta viscosidad esta dada por el aumento en la concentración de sales en el citoplasma, lo cual se explica por la salida de agua intracelular para compensar la congelación del agua extracelular y los efectos que ello produce en la estructura de la membrana por los cambios de presión osmótica. Este fenómeno puede llegar a un punto donde la concentración es tan alta que propicia la formación de precipitados. Simultáneamente a este proceso, si el enfriamiento es rápido se promueve la formación de cristales de hielo (6).

Se observa además que el frío debilita los enlaces hidrofóbicos de las proteínas, situación que esta determinada por los cambios físicos que suceden en la estructura del agua que compone el citosol y que actúa como solvente; A su vez, este fenómeno genera la inactivación de las enzimas alostéricas y de la actividad funcional de los ribosomas.

Estos cambios, que en organismos muy desarrollados puede significar un daño irreparable para su supervivencia, constituye para los microorganismos bacterianos un reto y muchos de ellos logran una adaptación que se traduce en fabricación de enzimas resistentes al frío, sistemas de transporte adaptados a bajas temperaturas e incluso una transformación en la membrana aumentando la proporción de fosfolípidos de membrana, específicamente en la cantidad de ácidos grasos insaturados o poliinsaturados lo que le permite mantener el estado semifluido de la membrana y evitar la congelación (6).

\section{Criopreservantes}

Las sustancias denominadas criopreservantes impiden por interacción molecular con el agua, la acción destructiva del congelamiento sobre las células, es decir, protegen de la formación de cristales de hielo con un grado bajo de toxicidad para las células vivas (3).

Una de las hipótesis en las cuales se basa el efecto de los criopreservantes es en que las características físico-químicas de estas sustancias le confieren afinidad por el agua molecular y de esa forma atrapar la molécula de agua en su interior, lo que impide que el agua forme cristales geométricos ordenados; en consecuencia, la solidificación del medio se establece con una distribución molecular desordenada del agua y la sustancia toma el carácter de sustancia vítrea protectora(4-5).

Las sustancias más utilizadas en la conservación bacteriana a bajas temperaturas se encuentran:

1. Sustancias no ionizables de bajo peso molecular que provocan solidificación amorfa y vítrea en lugar de cristalización para evitar la formación de zonas intracelulares con alta concentración de sales para evitar la deshidratación celular: glicerol, sacarosa, lactosa, DMSO (dimetilsulfóxido), entre otros

2. Sustancias ricas en proteína como la leche, suero, extracto de carne

3. Proteínas purificadas como la albúmina

4. Macromoléculas no proteicas como PVP (polivinilpirrolidona) y dextranos

Algunos de los criopreservantes presentan toxicidad para la célula viva a temperatura ambiente, 
por lo tanto en los procesos de congelación y descongelación se debe tener en cuenta los tiempos de exposición de las células a estas sustancias.

\section{Referencias}

1. Madigan M, Martinko J, Parker Brock. Biología de los microorganismos. Novena edición, Editorial Prentice hall. Madrid 2004. 62p.

2. Mukamolova G, Kaprelyants A, Douglas B. Young Michael. Adoption of the transiently non-culturable state- a bacterial survival strategy? Advances in Applied Microbiology. 2003; 47: $65-129$.

3. Hubalek Z. Review. Protectants used in the cryopreservation of microorganisms. Criobiology. 2003;46: 205-229.

4. García L, Scherer C, Rodríguez R. Líquidos sobreenfriados y vidrios. La ciencia para todos biblioteca digital. Física. Fondo de Cultura Económica. México.1991.

5. Van P, Thevelein J. Determinants of freeze tolerance in microorganisms, physiological importance and biotechnological applications. Advances in Applied Microbiology. 2003;53: 129 $-176$.

6. Bouachanh T, Jean P, Desmasures N, Micheline G, Jean, P. Resin straw as an alternative system to securely store frozen microorganisms. Journal of Microbiological Methods. 2004;57:181 - 186 .

7. Alexandre G, Greer S, Zhulin I. Ecologial role of energy taxis in microorganisms. Microbiology Reviews. 2003;(28):113 126.

8. Pettersson M, Baath E. Temperature-dependent changes in the soil bacteria community in limed and unlimed soil. FEMS Microbiology ecology. 2003;(45) : 13 - 21.

9. Smalla K, Sobecky P. The prevalence and diversity of mobile genetic elements in bacterial communities of different environmental habitats: insights gained front different methodological approaches. FEMS Microbiology ecology. 2002;42:165 - 175 .

10. Lehninger .Biological membranes and cytoplasm. Biochemistry . 369-420p.

11. Madigan M, Marrs B. Extremófilos. Inv y Ciencia.2003;249: 60-66.

12. Matin A, Anger P, Blum J, Schultz E. Genetic basis of starvation survival in nondifferentiating bacteria. Ann.Rev. Microbiol. 1989; 43: 293-316. 